\title{
Contribution of some Mediterranean plants to BVOC in the atmosphere of an open and a closed environment: a preliminary study
}

\author{
E. Ormeño Lafuente, C. Fernandez, C. Robles, A. Bousquet-Mélou, \\ B. Vila, S. Greff \& G. Bonin \\ IMEP, Institut Méditerranéen d'Ecologie et Paléoécologie, UMR 6116 \\ CNRS, University of Provence, Marseille, France
}

\begin{abstract}
Terpenes (monoterpenes and sesquiterpenes) were measured under a closed environment (with a canopy structure) and an open environment (without a canopy structure). Terpenes were sampled both directly from vegetation (Cistus albidus, Rosmarinus officinalis, Pinus halepensis and Quercus coccifera) and in the atmosphere. Results show that the four species are influenced by the environmental structure. This influence is especially important for $Q$. coccifera and $R$. officinalis which present higher emission rates at the open and the closed environment, respectively. Of special interest is the fact that sesquiterpene emissions of $C$. albidus and $P$. halepensis are higher under the open environment, since it may indicate that these compounds are dependent on light. Terpenes do not follow a lengthwise gradient in the atmosphere. However, some exceptions have been found for $\alpha$-pinene and sesquiterpene concentrations. Monoterpene concentrations are significantly higher in the open atmosphere. This demonstrates that the canopy does not minimize terpene volatilization and that terpene concentration in the atmosphere is mostly dependent on plant contribution but litter seems to be another important source of terpenes.

Keywords: canopy, monoterpenes, sesquiterpenes, litter, $\alpha$-pinene, Q. coccifera, R. officinalis, $P$. halepensis, C. albidus.
\end{abstract}

\section{Introduction}

Biogenic volatil organic compounds (BVOC) from plants strongly contribute to the total release of VOC emissions to the atmosphere, mainly during summer 
months, when they outstrip anthropogenic VOC emissions [1]. Among them, terpenes are precursors of some oxydative agents, such as ozone from the troposphere [2]. The Mediterranean region, with its climatic conditions, high emitter species and industrial and population concentration, is recognized as a major source of tropospheric ozone in Europe [3].

BVOC of plants are of great variability, partly because of the numerous factors influencing them. Thus, the scientific community all over the world and particularly in the Mediterranean Region (e.g. BEMA project [4], ESCOMPTE [5]), has devoted considerable effort on describing the effects of several abiotic and biotic factors on these emissions. Temperature, radiation [6] and seasonal cycles [7] are the factors most frequently studied. Many other factors, such as other pollutants $\left(\mathrm{O}_{3}\right)$ [8], ecosystem type [9], age [10] or drought [11], have also been related to $\mathrm{BVOC}$ emissions.

Since canopy acts as a factor having an impact on light and temperature [12], we have studied the influence of the environmental structure (with or without canopy) on terpenes released from plants. We have also considered the possibility that canopy acts as a physical barrier to terpene volatilization. For this, we have measured terpene concentrations in the two types of atmosphere. For this second aim, measurements were developed following a lengthwise gradient in order to determine if terpene concentrations were or not homogenous at different levels.

Studying BVOC directly in the atmosphere is a new approach, since BVOC of plants are traditionally focalized on direct emissions from plants.

\section{Materials and methods}

\subsection{Species, experimental site conditions and sampling description}

Measurements were conducted in an open and a closed environment of a garrigue ecosystem in the south of France (Valabre) (distance between the two environments: $150 \mathrm{~m}$ ). Vegetation for both environments was mainly represented by Quercus coccifera L., but Rosmarinus officinalis L., Pinus halepensis Mill, and Cistus albidus L., were also strongly widespread. The four studied species represented more than $80 \%$ of total vegetation.

Two different measurements were made at each environment (i) direct terpene emissions of the studied species (ii) terpenes in the atmosphere. For direct emissions, seven plants per species were sampled between 13:00 and 15:00 (solar time). In the atmosphere, measurements were conducted at four levels (litter, few centimeters above plants, 4 meters and below canopy or the equivalent in the open environment) at 13:00 (s.t) for 1 hour. Four horizontal samples per level were taken. All measurements were conducted from July 16 to July 20. Climatic conditions of those days were similar: hot-clean sky, 1220$1600 \mu \mathrm{mol} . \mathrm{m}^{2} . \mathrm{s}^{-1} \mathrm{PAR}$ (photosynthetic active radiation), $36-40{ }^{\circ} \mathrm{C}$ at a sun exposed position and no or slight wind (max. $10 \mathrm{~m} \cdot \mathrm{s}^{-1}$ ). 


\subsection{Sampling system and terpene analysis}

A Teflon chamber enclosure system $(0,51)$ was used to sample terpenes directly emitted from a single branch per plant. At the air stream inlet of each Teflon chamber pure air $(99 \%)$ was flushed for $15 \mathrm{~min}$ at $100 \mathrm{ml} . \mathrm{min}^{-1}$. At the air stream outlet, one Tenax TA per Teflon chamber was used, and air was pumped for 10 min at $80 \mathrm{ml} . \mathrm{min}^{-1}$ so that terpenes are trapped. The system was constructed to allow 14 measurements simultaneously.

The sampling system used to trap terpenes from the atmosphere, a part of the above described system, consisted of a 16 tube-system from which air is pumped. At the air stream outlet of each tube, a Tenax TA is used and pumping took place for $1 \mathrm{~h}$ at $30-80 \mathrm{ml} \cdot \mathrm{min}^{-1}$ so that total sampled volume does not outstrip 3litres. We focussed on monoterpenes and sesquiterpenes which were analysed through thermal desorption by gas chromatography (GC) fitted with a flame ionization detector (FID). Most peak identification and quantitation was achieved by direct injection of terpene solutions in cyclohexane. These solutions were prepared from commercial authentic terpenes of high purity ( $\sim 97 \%)$.

\section{Results and discussion}

\subsection{PAR and temperature under the open and the closed environment}

Canopy structure has an effect on temperature. At the open environment it is $4^{\circ} \mathrm{C}$ (environmental temperature) or $6^{\circ} \mathrm{C}$ (chamber temperature) higher than at the closed environment. Though, canopy structure more particularly limits light. Light through PAR is between 50-100 $\mu$ mol. $\mathrm{m}^{-2} . \mathrm{s}^{-1}$ at the closed environment, while it is between $1220-1600 \mu \mathrm{mol} . \mathrm{m}^{-2} . \mathrm{s}^{-1}$ at the open environment.

\subsection{Direct terpene emissions of plants under the open and the closed environment}

The four species are mainly monoterpene emitters (Figure 1) and their main emitted compound is the $\alpha$-pinene. Emissions of $Q$. coccifera (monoterpenes and total emissions), $C$. albidus (sesquiterpenes) and $P$. halepensis (sesquiterpenes) are significantly higher under the open environment (Figure 1, t Student test, $\mathrm{p}<0,05$ ), while emissions of $R$. officinalis (monoterpenes, sesquiterpenes and total emissions) are significantly higher under the closed environment (Figure 1, t Student, $\mathrm{p}<0,05)$.

These results agree with previous studies. Thus, Mediterranean oaks (Quercus section Sclerophyllodris), such as $Q$. coccifera, are known to produce monoterpenes in a light-dependent way, what agree with the fact that emissions of this species are higher at the open environment. Monoterpene emissions in a light-dependent way is apparently confined to the Mediterranean oaks, while it does not occur in other European or North American oaks [13]. In contrast, $R$. officinalis emissions are known to just depend on temperature $[14,15]$. 
Although, even if temperature was lower at the closed environment, emissions of this species are higher under this environment. Indeed, each species presents a temperature up to which emissions increase and then, emissions decline at higher temperatures [16].

The fact that sesquiterpenes of $C$. albidus and $P$. halepensis are higher at the open environment is of special interest since it has never been shown their dependence neither to light nor to temperature. This dependence has just been demonstrated for monoterpenes [17]. Thus, traditional algorithms used to standardize monoterpene emissions [18-20], are also used to standardize sesquiterpene emissions [21].

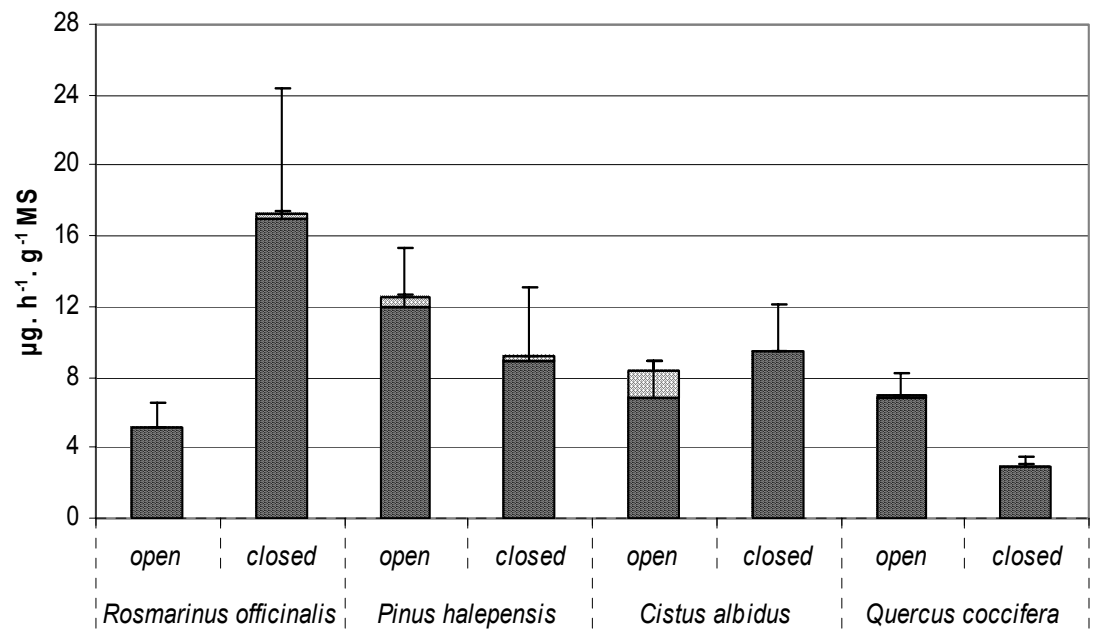

\section{Monoterpenes $\square$ Sesquiterpenes}

Figure 1: Monoterpenes and sesquiterpenes emitted by $C$. albidus, $R$. officinalis, $P$. halepensis and $Q$. coccifera under an open and a closed environment. (Bars indicate the standard error) $(n=7)$.

\subsection{Terpene concentrations in an open and a closed atmosphere}

Globally terpene concentrations are homogenous both, at the open and the closed atmosphere (Figure 2, two factors ANOVA, p>0,05). Nevertheless, we have found two exceptions. Firstly, sesquiterpene concentrations are higher several $\mathrm{cm}$ above plants that $4 \mathrm{~m}$ above ground, but this result has just been found in the open environment (Figure 2) (significant interaction between environment type and level sampling, one factor ANOVA, open environment, $\mathrm{p}<0,05$ ). Moreover, $\alpha$-pinene, which represents $50 \%$ of total monoterpenes, reaches significant higher concentrations at the litter level (mean $\left.=0,37 \mu \mathrm{g} .1^{-1}\right)$ than at the other three levels (mean=0,14 $\mu \mathrm{g} .1^{-1}$ ) (Figure 2, two factors ANOVA, level, $\mathrm{p}<0,05$ ) in the two atmospheres. 


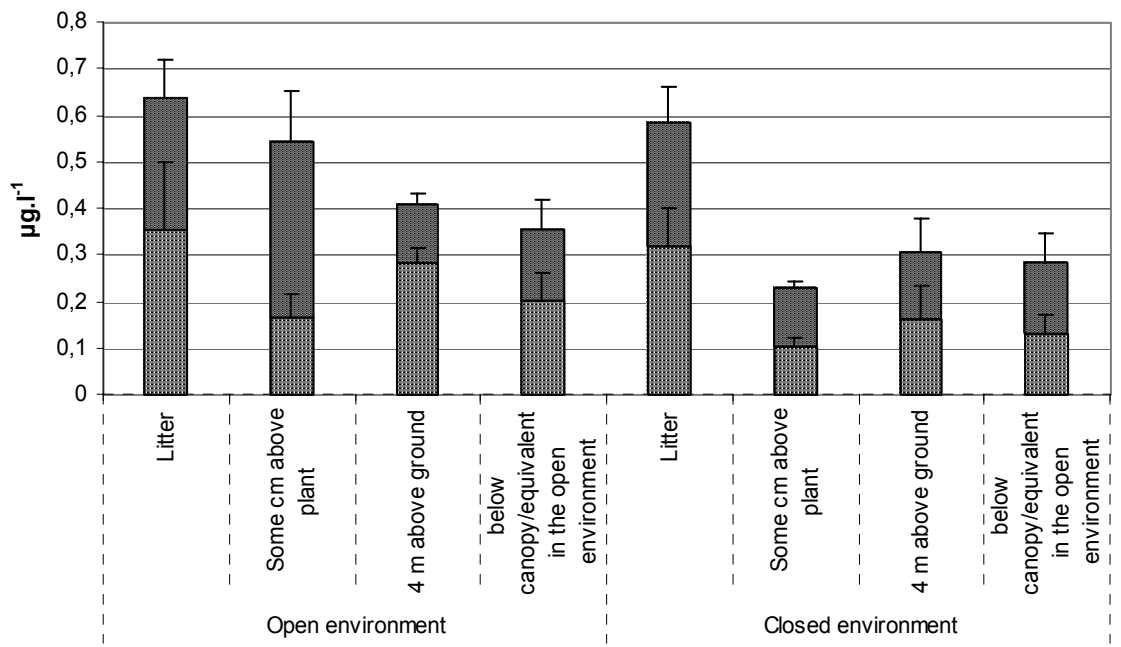

Figure 2: $\quad$ Mean concentrations of $\alpha$-pinene and total monoterpenes along a lengthwise gradient in an open and a closed atmosphere. (Bars indicate the standard error, $\mathrm{n}=4$ ).

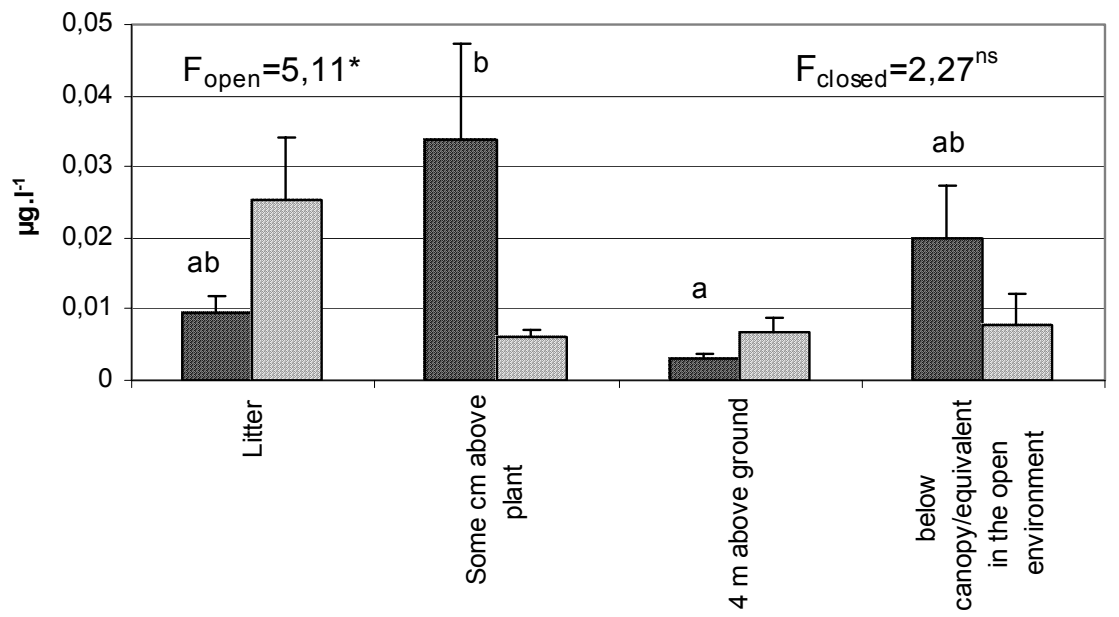

Open atmosphre $\square$ Closed atmosphere

Figure 3: One factor ANOVA about mean sesquiterpene concentrations along a lengthwise gradient in an open and a closed atmosphere. (Bars indicate the standard error, $\mathrm{n}=4$ ). Results of post hoc Tukey test are also shown. Different letters indicate that valeurs are significantly different at $95 \%$ of confidence. $a<b$. 
Little information is available about BVOC released from litter. However, some authors have pointed out the importance of taking litter into account for obtaining more accurate terpene estimations [22].

While we have found no differences for sesquiterpenes between the two atmospheres (Two factor ANOVA, environmental structure, $p>0,05$ ), monoterpene concentrations are significantly higher at the open atmosphere, (Two factor ANOVA, environmental structure, $\mathrm{p}<0,05$ ). Thus, mean monoterpene concentrations is: $0,49 \pm 0,06 \mu \mathrm{g} . \mathrm{l}^{-1}$ at the open atmosphere (standard error) and 0,35 $\pm 0,06 \mu \mathrm{g} . \mathrm{l}^{-1}$; at the closed atmosphere, when all (Figure 4).

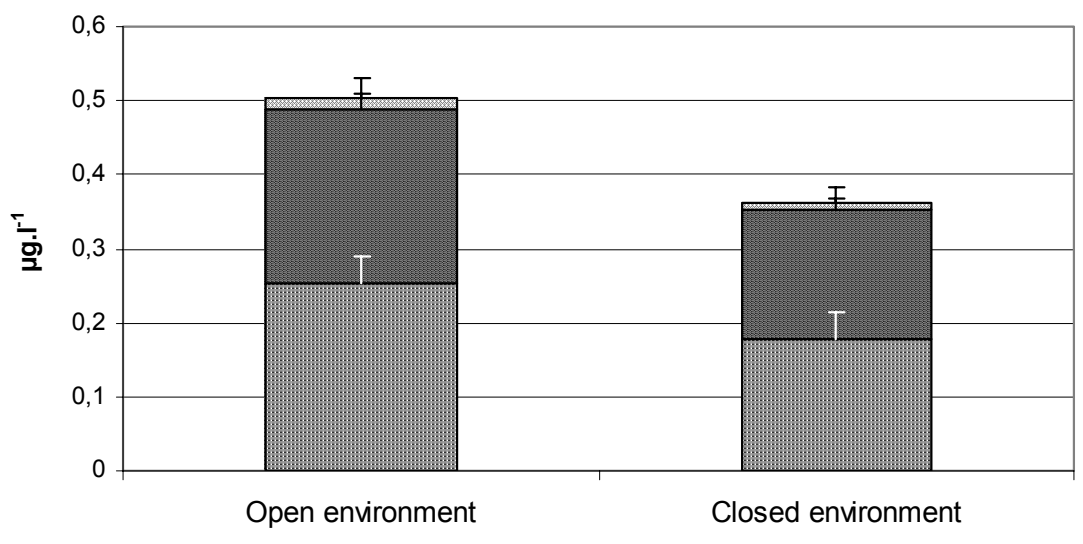

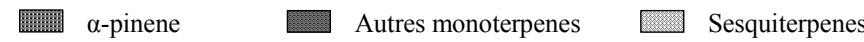

Figure 4: Mean concentrations of $\alpha$-pinene, total monoterpenes and sesquiterpenes in an open and a closed atmosphere, all level samplings taken together (Bars indicate the standard error, $\mathrm{n}=12$ ).

In conclusion, the four studied species are directly influenced by the presence or the absence of a canopy structure, since it strongly modifies temperature and light conditions. Moreover, canopy structure does not act as a physical barrier for terpenes, since monoterpene concentrations are higher at the open atmosphere. Therefore, plant contribution appears to be the main source of terpenes in the atmosphere, but litter could also be an important source of atmospheric BVOC. Thus, concentrations and composition of BVOC in the atmosphere are likely different depending on species composition and abundance. In consequence, the higher monoterpene concentrations here found in the open atmosphere, seem to be linked to be fact that the two environments are mainly represented by $Q$. coccifera, and that monoterpene emissions of this species are strongly favoured by light. In consequence, linking both, plant composition and species-specific emission variation according to light and temperature, could be of great interest for estimating BVOC concentrations in open (e.g. shrub environment) and closed environments (e.g. pine forest). 
These scenarios at the environmental scale, emphasizes the need for detailed information about (i) factors affecting BVOC emissions for different species (ii) other biogenic emission sources (e.g. litter), in order to improve inputs of BVOC emissions to tropospheric chemistry model.

\section{References}

[1] Simon, V., Luchetta, L., and Torres, L., 2001. Estimating the emission of volatile organic compounds (VOC) from the French forest ecosystem. Atmospheric Environment. 35(Supplement 1): p. S115-S126.

[2] Fuentes, J.D., Lerdau, M., Atkinson, R., Baldocchi, D., Bottenheim, J.W., Ciccioli, P., Lamb, B., Geron, C., Gu, L., Guenther, A., Sharkey, T.D., and Stockwell, W., 2000. Biogenic hydrocarbons in the atmospheric boundary layer: A review. Bulletin of the American Meteorological Society. 81(7): p. 1537-1575.

[3] Millan, M., Salvador, R., Mantilla, E., and Artiñano, B., 1996. Meteorology and phytochemical air pollution in southern Europe: experimental results from EC research projects. Atmospheric Environment. 30 (12): p. 1909-1924.

[4] Owen, S.M. and Hewitt, N.H., 2000. Extrapolating branch enclosure measurements to estimates of regional scale biogenic VOC fluxes in the northwestern Mediterranean basin. Journal of Geophysical Research. 105 (D9)(16 May): p. 11,573-11,583.

[5] Simon, V., Dumergues, L., Solignac, G., and Torres, L., 2005. Biogenic emissions from Pinus halepensis: a typical species of the Mediterranean area. Atmospheric Environment. 74: p. 37-48.

[6] Sabillon, D. and Cremades, L.V., 2001. Diurnal and seasonal variation of monoterpene emission rates for two typical Mediterranean species (Pinus pinea and Quercus ilex) from field measurements - relationship with temperature and PAR. Atmospheric Environment. 35(AVRIL): p. 44194431.

[7] Staudt, M., Bertin, N., Frenzel, B., and Seufert, G., 2000. Seasonal variation in amount and composition of monoterpenes emitted by young Pinus pinea trees-Implications for emission modelling-. Journal of atmospheric chemistry. 33: p. 77-99.

[8] Penuelas, J., Llusia, J., and Gimeno, B.S., 1999. Effects of ozone concentrations on biogenic volatile organic compounds emission in the Mediterranean region. Environmental Pollution. 105(1): p. 17-23.

[9] Drewitt, G.B., Curren, K., Steyn, D.G., Gillespie, T.J., and Niki, H., 1998. Measurement of Biogenic hydrocarbon emissions from vegetation in the Lower Fraser Valley, British Columbia. Atmospheric Environment. 32, $\mathrm{N}^{\circ}$ 20: p. 3457-3466.

[10] Street, R.A., Owen, S., Duckham, S.C., Boissard, C., and Hewitt, C.N., 1997. Effect of habitat and age on variations in volatile organic compound (VOC) emissions from Quercus ilex and Pinus pinea. Atmospheric Environment. 31: p. 89-100. 
[11] Hansen, U. and Seufert, G., 1999. Terpenoid emission from Citrus sinensis (L.) OSBECK under drought stress. Physics and Chemistry of the Earth Part B-Hydrology Oceans and Atmosphere. 24(6): p. 681-687.

[12] Schaab, G., Steinbrecher, R., Lacaze, B., and Roman, L., 2000. Assessment of long-term vegetation changes on potential isoprenoid for a Mediterranean-type ecosystem in France. Journal of Geophysical Research. 105 (D23): p. 28,863-28,873.

[13] Lerdau, M. and Gray, D., 2002. Ecology and evolution of light-dependent and light-independent phytogenic volatile organic carbon. New Phytologist. 157: p. 199-211.

[14] Llusià, J. and Peñuelas, J., 2000. Seasonal patterns of terpene content and emission from seven Mediterranean woody species in field conditions. American Journal of Botany. 87: p. 133-140.

[15] Owen, S.M., Harley, P., Guenther, A., and Hewitt, C.N., 2002. Light dependency of VOC emissions from selected Mediterranean plant species. Atmospheric environment. 36: p. 3147-3159.

[16] Staudt, M. and Bertin, N., 1998. Light and temperature dependence of the emission of cyclic and acyclic monoterpenes from Holm oak (Quercus ilex L.) leaves. Plant, Cell and Environment. 21: p. 385-395.

[17] Llusià, J. and Peñuelas, J., 1999. Pinus halepensis and Quercus ilex terpene emission as affected by temperature and humidity. Biologia Plantarum. 42 (2): p. 317-320.

[18] Guenther, A.B., Zimmerman, P.R., Harley, P.C., Monson, R.K., and Fall, R., 1993. Isoprene and Monoterpene Emission Rate Variability - Model Evaluations and Sensitivity Analyses. Journal of Geophysical ResearchAtmospheres. 98(D7): p. 12609-12617.

[19] Guenther, A., Hewitt, C.N., Erickson, D., Fall, R., Geron, C., Graedel, T., Harley, P., Klinger, L., Lerdau, M., Mckay, W.A., Pierce, T., Scholes, B., Steinbrecher, R., Tallamraju, R., Taylor, J., and Zimmerman, P., 1995. A Global-Model of Natural Volatile Organic-Compound Emissions. Journal of Geophysical Research-Atmospheres. 100(D5): p. 8873-8892.

[20] Tingey, D.T., Manning, M., Grothaus, L.C., and Burns, W.F., 1980. Influence of light and temperature on monoterpene emission rates from slash pine. Plant Physiology. 65: p. 797-807.

[21] Peñuelas, J. and Llusià, J., 1999. Short term responses of terpene emissions rates to experimental changes of PFD in Pinus halepensis and Quercus ilex in summer field conditions. Environmental and experimental Botany. 42: p. 61-68.

[22] Isidorov, V.A., Vinogorova, V.T., and Rafalowski, K., 2003. HS-SPME analysis of volatile organic compounds of coniferous needle litter. Atmospheric Environment. 37(33): p. 4645-4650. 